\title{
GERAKAN LITERASI DI NAGARI SUNGAI NYALO
}

\author{
Hera Hastuti dan Zafri \\ Email: herahastuti@fis.unp.ac.id \\ Jurusan Sejarah Fakultas Ilmu Sosial Universitas Negeri Padang
}

\begin{abstract}
Abstrak
Artikel ini diramu dari program pengabdian masyarakat yang sedang tim laksanakan di Nagari Sungai Nyalo. Rendahnya tingkat pendidikan anak-anak Nagari Sungai Nyalo di Kabupaten Pesisir Selatan dibandingkan dengan daerah atau nagari sekitarnya merupakan latar belakang dilaksanakannya program gerakan literasi. Salah satu faktor penyebabnya adalah kurangnya motivasi belajar anak-anak untuk melanjutkan studi ke jenjang yang lebih tinggi, selain faktorfaktor lain yang juga sangat berpengaruh, seperti kehidupan sosial, ekonomi, dan budaya masyarakatnya. Gerakan literasi merupakan salah satu solusi dalam menghadapi persoalan pendidikan di Nagari Sungai Nyalo. Apalagi jika dilihat lebih jauh, Sungai Nyalo sedang bergiat dalam bidang pariwisatanya.
\end{abstract}

Kata Kunci: Gerakan, Literasi, Motivasi belajar, Pendidikan.

\section{Pendahuluan}

Pada dasarnya, literasi bukanlah suatu istilah baru, akan tetapi bagi sebagian orang, kata literasi masih asing, dan belum diketahui maknanya. Hal ini tidaklah mengherankan karena literasi memiliki makna yang komplek dan dinamis. Menurut KBBI, literasi adalah kemampuan menulis dan membaca, pengetahuan atau keterampilan dalam bidang atau aktivitas tertentu, dan kemampuan individu dalam mengolah informasi dan pengetahuan untuk kecakapan hidup.

Survey yang lakukan oleh UNESCO terhadap minat baca masyarakat Indonesia sangat memprihatinkan, hanya 0,001\%. Artinya dari 1000 orang Indonesia, cuma satu orang yang rajin membaca. Riset lainnya bertajuk "Most Littered Nation In the World" yang dilakukan oleh Central Connecticut State University pada Maret 2016 lalu, Indonesia dinyatakan menduduki peringkat ke 60 dari 61 negara soal minat membaca. Ini artinya, Indonesia persis berada di bawah Thailand (59) dan di atas Bostwana (61). Padahal dari segi penilaian infrastruktur untuk mendukung pembaca peringkat Indonesia berada di atas negara- negara Eropa.

Menghadapi permasalahan dan fenomena di atas, salah satu upaya yang bisa dilakukan dalam menumbuhkan minat baca pada anak yaitu dengan membuat gerakan literasi. Pemilihan 
Sungai Nyalo sebagai salah satu lokasi gerakan literasi bukanlah tanpa alasan. Hasil observasi dan survey yang dilakukan di Nagari Sungai Nyalo, menyimpulkan bahwa; Rendahnya minat baca atau kemampuan literasi anak karena tidak adanya fasilitas memadai untuk membaca, khusunya minimnya buku bacaan, apalagi buku yang khusus ditujukan untuk anak-anak.

Pelaksanaan gerakan literasi untuk menumbuhkan minat baca pada anak Sungai Nyalo, yakni dengan mensuplai buku-buku bacaan, khususnya buku bacaan untuk anak-anak, melakukan penyuluhan pada orang tua agar ikut memotivasi anak untuk membaca, membuat perpustakaan mini yang selalu bisa digunakan oleh anak untuk membaca dengan bekerja sama dengan pemerintahan nagari.

\title{
Pembahasan
}

\section{A. Geografis Sungai Nyalo}

Kabupaten Pesisir Selatan merupakan salah satu dari 19 Kabupaten/Kota di Provinsi Sumatera Barat dan terletak di bagian Selatan Provinsi Sumatera Barat. Secara geografis Kabupaten Pesisir Selatan terletak pada koordinat $0^{\circ} 59^{\prime}-2^{\circ} 28,6^{\prime}$ Lintang Selatan dan $100^{\circ}$ 19' - $101^{\circ} 18^{\prime}$ Bujur Timur, dan memiliki luas wilayah $\pm 5.794,89 \mathrm{~km}^{2}$ atau sebesar 13,70\% dari luas wilayah Provinsi Sumatera Barat, termasuk di dalamnya sekitar 25 pulau (kecil), serta luas perairan (laut) $\pm 84,312 \mathrm{~km}^{2}$ dengan panjang pantai $\pm 234 \mathrm{~km}$ yang memiliki 47 pulau-pulau kecil dengan luas $\pm 1.212,67 \mathrm{~km}^{2}$.

Kabupaten Pesisir Selatan dibentuk berdasarkan Undang-Undang Nomor 12 Tahun 1956 tentang Pembentukan Daerah Otonomi Kabupaten dalam Lingkungan Daerah Provinsi Sumatera Tengah. Untuk kondisi topografi atau ketinggian tanah berkisar antara $0-1.000$ meter di atas permukaan laut $(\mathrm{dpl})$. Daerah ini merupakan dataran rendah dan berbukit, yang merupakan perpanjangan dari Bukit Barisan. Batas-batas wilayah Kabupaten Pesisir Selatan secara geografis sebagai berikut :

\author{
Sebelah Utara : Kota Padang \\ Sebelah Selatan : Kabupaten Muko-Muko (Provinsi Bengkulu); \\ Sebelah Timur $\quad$ : Kabupaten Solok, Solok Selatan dan Kerinci \\ Sebelah Barat : : : Samudera Indonesia.
}


Secara administrasi terdiri dari 15 Kecamatan dan 182 Nagari, lebih jelasnya mengenai letak dan luas wilayah dapat dilihat pada berikut,

Tabel 1: Luas Berdasarkan Kecamatan

\begin{tabular}{|c|l|c|c|r|r|}
\hline No & \multicolumn{1}{|c|}{ Kecamatan } & Nagari & Kampung & Luas Wilayah $\left.\mathbf{( K m}^{2}\right)$ & Persentase \\
\hline 1 & Silaut & 10 & 27 & 365,50 & 6,36 \\
\hline 2 & Lunang & 10 & 28 & 564,00 & 9,81 \\
\hline 3 & Basa IV Balai Tapan & 10 & 20 & 300,93 & 5,23 \\
\hline 4 & Ranah IV Hulu Tapan & 10 & 20 & 376,57 & 6,55 \\
\hline 5 & Pacung Soal & 10 & 24 & 426,10 & 7,41 \\
\hline 6 & Airpura & 10 & 20 & 314,00 & 5,46 \\
\hline 7 & Linggo Sari Baganti & 16 & 43 & 315,41 & 5,49 \\
\hline 8 & Ranah Pesisir & 10 & 27 & 564,39 & 9,82 \\
\hline 9 & Lengayang & 9 & 45 & 590,60 & 10,27 \\
\hline 10 & Sutera & 12 & 32 & 445,65 & 7,75 \\
\hline 11 & Batang Kapas & 9 & 29 & 359,07 & 6,24 \\
\hline 12 & IV Jurai & 20 & 52 & 373,80 & 6,50 \\
\hline 13 & Bayang & 17 & 45 & 77,50 & 1,35 \\
\hline 14 & IV Nagari Bayang Utara & 6 & 17 & 250,74 & 4,36 \\
\hline 15 & Koto XI Tarusan & 23 & 51 & 425,63 & 7,40 \\
\hline \multicolumn{2}{|c|}{ Jumlah } & $\mathbf{1 8 2}$ & $\mathbf{4 8 0}$ & $\mathbf{5 . 7 9 4 , 8 9}$ & $\mathbf{1 0 0 , 0 0}$ \\
\hline
\end{tabular}

Sumber : Kabupaten Pesisir Selatan Dalam Angka, 2016

Dari jumlah nagari dan kampung, Kecamatan Koto XI Tarusan merupakan nagari yang terbanyak yaitu, mempunyai 23 (dua puluh tiga) nagari dan 51 (lima puluh satu) kampung. Kecamatan Koto XI Tarusan merupakan daerah paling utara dari Kabupaten Pesisir Selatan. Secara geografis terletak pada $0^{\circ} 59,00^{\prime}$ - $1^{\circ} 17,30^{\prime}$ Lintang Selatan dan $100^{\circ} 19,00^{\prime}-100^{\circ}$ 34,70' Bujur Timur. Batas administrasi wilayah Kecamatan Koto XI Tarusan sebagai berikut :

Sebelah Utara : Kota Padang

Sebelah Selatan : Kecamatan Bayang dan Kecamatan Bayang Utara

Sebelah Timur $\quad$ : Kabupaten Solok; dan

Sebelah Barat $\quad$ : Kabupaten Kepulauan Mentawai.

Luas wilayah darataan Kecamatan Koto XI Tarusan yaitu sekitar 425,63 $\mathrm{Km}^{2}$ atau 42.563 dan secara administratif terdiri dari 23 Nagari. Untuk lebih jelasnya mengenai wilayah administrasi Kecamatan dapat dilihat pada tabel berikut. 


\section{Luas Daerah Menurut Nagari}

\begin{tabular}{|c|c|c|c|}
\hline No & Nagari & $\begin{array}{r}\text { Luas Wilayah } \\
\left(\mathrm{Km}^{2}\right)\end{array}$ & Persentase \\
\hline 1 & Kapuh & 12,20 & 2,87 \\
\hline 2 & Kapuh Utara & 9,42 & 2,21 \\
\hline 3 & Jinang Kampung Pansur Ap.Pulai & 4,60 & 1,08 \\
\hline 4 & Ampang Pulai & 6,00 & 1,41 \\
\hline 5 & Pulau Karam Ap. Pulai & 4,00 & 0,94 \\
\hline 6 & Cerocok Anau Ap. Pulai & 15,01 & 3,53 \\
\hline 7 & Nanggalo & 4,01 & 0,94 \\
\hline 8 & Setara Nanggalo & 24,71 & 5,81 \\
\hline 9 & Batu Hampa Selatan & 8,91 & 2,09 \\
\hline 10 & \begin{tabular}{|l} 
Batu Hampa \\
\end{tabular} & 7,00 & 1,64 \\
\hline 11 & Duku & 20,41 & 4,80 \\
\hline 12 & Mandeh & 6,48 & 1,52 \\
\hline 13 & Sungai Nyalo Mudiak Aia & 21,34 & 5,01 \\
\hline 14 & Sungai Pinang & 29,15 & 6,85 \\
\hline 15 & Duku Utara & 10,41 & 2,45 \\
\hline 16 & Br. Balantai Selatan & 15,52 & 3,65 \\
\hline 17 & Br. Belantai Tengah & 15,60 & 3,67 \\
\hline 18 & Br. Belantai & 17,02 & 4,00 \\
\hline 19 & Br. Belantai Timur & 15,12 & 3,55 \\
\hline 20 & $\begin{array}{l}\text { Kampung Baru Korong Nan } \\
\text { Ampek }\end{array}$ & 22,36 & 5,25 \\
\hline 21 & Teratak Sungai Lundang & 80,64 & 18,95 \\
\hline 22 & Siguntur Tua & 19,50 & 4,58 \\
\hline 23 & Siguntur & 56,22 & 13,21 \\
\hline & Jumlah & 425,63 & 100,00 \\
\hline
\end{tabular}

Sumber : Kecamatan Koto XI Tarusan Dalam Angka, Tahun, 2016

Salah satu nagari yang terletak di Kecamatan Koto XI Tarusan adalah Nagari Sungai

Nyalo Mudiak Aie. Sebagaimana diketahui, Nagari Sungai Nyalo oleh Kementerian Desa, 
Pembangunan Daerah Tertinggal dan Transmigrasi pada tahun 2016 ditetapkan sebagai desa dengan perkembangan wisata tercepat di Indonesia. Nagari Sungai Nyalo juga merupakan Desa Binaan Universitas Negeri Padang yang dikomandoi oleh Dr. Siti Fatimah, M.Pd.,M.Hum. Masuknya Nagari Sungai Nyalo sebagai Desa Binaan, menjadikan programprogram pengabdian yang dilaksanakan di Sungai Nyalo dapat terealisasi dengan maksimal.

Nagari Sungai Nyalo Mudiak Aia secara topografi berupa pengunungan dan dataran dengan ketinggian antara $10 \mathrm{~s} / \mathrm{d} 15$ meter di atas permukaan laut. Sebagaimana Indonesia pada umumnya, Nagari Sungai Nyalo mempunyai iklim kemarau dan penghujan, yang mempengaruhi pola tanam masyarakatnya. Nagari Sungai Nyalo memiliki dua kampung dan satu jorong, dengan jumlah penduduk lebih kurang sekitar 1268 jiwa dengan 1071 KK (sungainyalomudiakaia.sideka.id, akses 10 April 2019).

\section{B. Sungai Nyalo dan Permasalahannya}

Pesatnya perkembangan pariwisata di Nagari Sungai Nyalo, belum diimbangi dengan perkembangan pendidikannya. Rendahnya minat baca anak-anak usia sekolahan juga menjadi faktor penyebab masih rendahnya kualitas pendidikan. Pada hakikatnya terdapat beberapa faktor yang mempengaruhi minat baca pada anak, salah satunya adalah lingkungan hidup. Seperti yang dilansir dalam situs gramedia.com (akses, 10 April 2019), menyatakan bahwa lingkungan hidup di sekitar anak merupakan faktor penting dalam kehidupan, karena secara tidak langsung lingkungan sekitarlah yang membentuk kebiasaan anak. Lingkungan keluarga misalnya, lingkungan ini adalah yang paling dekat dengan anak. Jika lingkungan keluarga 'membudayakan' membaca dan memiliki perencanaan tertentu dalam membeli buku bersama anak, maka bisa dipastikan si anak juga suka membaca. Akan tetapi bagi masyarakat kita, apalagi yang masih hidup didaerah yang belum baik akses untuk membaca, seperti tersedianya perpustakaan atau taman bacaan, toko buku dan semacamnya, sehinga minat membaca, khususnya pada anak-anak begitu sangat rendah.

Cukup besarnya angka masyarakat yang tergolong dalam keluarga tidak mampu, sekitar 828 jiwa, menyebabkan tingkat pendidikan lebih dominan hanya tamat Sekolah Dasar. Sedangkan yang melanjutkan pendidikan ke perguruan tinggi dan meraih gelar sarjana hanya sekitar 1,2\% (sungainyalomudiakaia.sideka.id, akses 10 April 2019). Sebuah angka yang 
sangat rendah jika dibandingkan dengan pertumbuhan pariwisata yang pesat di Nagari Sungai Nyalo.

Kebutuhan masyarakat Nagari Sungai Nyalo terhadap perencanaan pendidikan yang lebih baik, merupakan kebutuhan yang urgen. Hal ini melihat perkembangan pariwisata Sungai Nyalo yang semakin berkembang da diminati oleh wisatawan lokal dan manca negara. Jika pemerintah daerah mengabaikan tingkat pendidikan masyarakat, maka kemungkinan masyarakat Nagari Sungai Nyalo hanya sebagai pekerja kasar di nagarinya sendiri.

\section{Gerakan Literasi di Sungai Nyalo}

Rendahnya tingkat pendidikan anak-anak Nagari Sungai Nyalo, yang ditenggarai oleh rendahnya motivasi dan kurangnya sarana pendidikan (membaca). Padahal anak memiliki waktu luang yang cukup panjang setelah mereka pulang sekolah, sehingga umumnya mereka hanya bermain atau menonton televisi, yang kadang tontonannya tidak sesuai dengan umur mereka.

Peningkatan minat anak dalam bidang pendidikan, bisa dilakukan dengan berbagai cara, salah satunya yaitu dengan membuat program agar anak-anak Nagari Sungai Nyalo gemar membaca. Menghadirkan Gerakan Literasi dilingkungan masyarakat, merupakan salah satu solusi yang konkret dalam memotivasi minat membaca anak-anak Sungai Nyalo. Beberapa program yang diterapkan dalam gerakan literasi ini yaitu,

a)Membangun budaya literasi dengan menyediakan buku-buku bacaan anak-anak, baik berupa fiksi maupun non fiksi, dan buku-buku motivasi belajar.

b) Mengajak anak menulis dengan mengadakan lomba menulis yang diikuti oleh anak umur 6 - 15 tahun, dengan pembagian beberapa kategori.

c)Mengadakan penyuluhan secara berkelanjutan kepada orang tua di Nagari Sungai Nyalo, tentang pentingnya memotivasi anak untuk membaca dan menulis (belajar), demi perbaikan taraf kehidupan anak-anak mereka dimasa depan.

d) Pembangunan Rumah Literasi dikoordinasikan dengan Pemerintahan Nagari, mengenai lokasi dan tempat yang digunakan. Hal ini penting untuk memastikan keberlanjutan program gerakan literasi kedepannya.

715 | Seminar Nasional Sejarah ke 4 Jurusan Pendidikan Sejarah Universitas Negeri Padang 
Beberapa tahapan pelaksanaan gerakan literasi di Nagari Sungai Nyalo Mudik Aie Kabupaten Pesisir Selatan yakni,

1) Melakukan peninjauan kembali ke Nagari Sungai Nyalo, kemudian berkoordinasi dengan Pemerintah Nagari yang diwakili oleh Wali Nagari. Kesepakatan tersebut menyangkut hal-hal mengenai Gerakan Literasi, mulai dari lokasi kegiatan, sampai kajian keberlanjutan program gerakan literasi dengan pendirian perpustakaan oleh nagari.

2) Melaksanakan sosialisasi kepada orang tua dan wali murid anak-anak Nagari Sungai Nyalo tentang pentingnya literasi dalam keberlanjutan pendidikan anak dimasa depan. Motivasi literasi tidak hanya dilakukan hanya sekali dua kali, tetapi harus berkelanjutan, dan memiliki program-program capaian yang jelas dan terukur. Mulai dari mengajak anak gemar membaca, menekankan pentingnya budaya membaca untuk kehidupan yang lebih baik di masa depan.

3) Melaksanakan program gerakan literasi bagi anak-anak Nagari Sungai Nyalo, mulai dari memotivasi minat membaca pada anak, seperti menceritakan kisah-kisah teladan para tokoh bangsa yang gemar membaca dan memiliki banyak karya, seperti Hamka, Natsir, Agus Salim, Tan Malaka, Agus Salim, dan lain-lain.

4) Kemudian mengajak anak untuk menuliskan minimal dua paragraf tentang cita-citanya di masa depan, dan meminta mereka untuk membacakannya di depan teman-temannya.

5) Memberi pelatihan secara berkelompok, dan masing-masing kelompok dibantu oleh mahasiswa Jurusan Sejarah UNP bagimana menulis yang baik, mulai dari ide penulisan, dan mendesripsikan hal-hal yang dilihat dalam bentuk paragraf.

6) Pada tahap berikutnya, anak-anak juga diminta untuk menuliskan kegiatan sehari-harinya pada buku yang telah disediakan, dan menceritakannya kembali.

7) Membagikan buku secara gratis kepada anak-anak Nagari Sungai Nyalo, terutama bukubuku yang berkaitan dengan motivasi belajar, dan kisah-kisah keteladanan orang-orang hebat dalam meraih cita-citanya. Buku-buku ini sangat banyak dijual dengan harga terjangkau.

8) Setelah pembagian buku pada masing-masing anak, mereka diminta untuk menuliskan pendapat mereka tentang buku yang mereka baca, hal apa yang mereka sukai dari buku 716 | Seminar Nasional Sejarah ke 4 Jurusan Pendidikan Sejarah Universitas Negeri Padang 
tersebut.

Pelaksanaan program Gerakan Literasi di Nagari Sungai Nyalo dilakukan dalam dua kali pertemuan selama bulan Juli 2019. Adapun perbandingan kegiatan tersebut dalam hal keaktivan dan partisipasi anak pada penulisan; 1) cita-cita dimasa depan, 2) kegiatan seharihari, dan 3) tentang buku bacaan yang telah di baca, dapat dilihat pada diagram berikut,

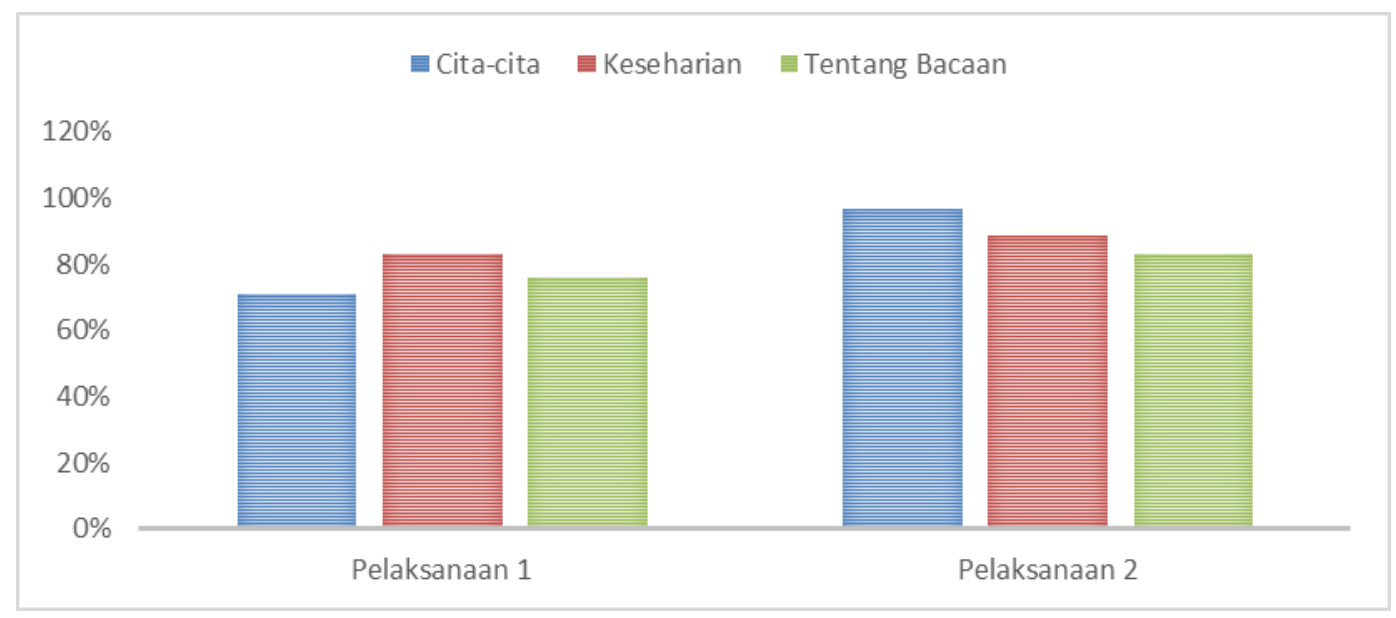

\section{Gambar 1: Grafik partisipasi dan keikutsertaan anak-anak Nagari Sungai Nyalo program gerakan literasi pada pelaksanaan 1 dan 2.}

Pada pelaksanaan 1 program gerakan literasi di Nagari Sungai Nyalo, jumlah anak-anak yang hadir yakni 42 orang, sedangkan pada pelaksanaan 2 yang hadir sebanyak 36 orang. Dari 42 orang anak pada pertemuan 1, yang menulis tentang cita-citanya sebanyak 30 orang (sekitar $71 \%$ ), menulis tentang kegiatan sehari-hari berjumlah 35 orang (83\%), dan tentang buku bacaan sebanyak 32 orang (76\%). Pada pelaksanaan 2, jumlah anak yang hadir sebanyak 36 orang, menulis cita-cita sebanyak 34 orang (94\%), kegiatan sehari-hari sebanyak 32 orang (89\%), dan tentang buku bacaan sebanyak 30 orang $(83 \%)$.

\section{Simpulan}


Dari perbandingan pelaksanaan 1 dan 2, terlihat ada peningkatan keaktifan dan partisipasi anakanak Nagari Sungai Nyalo dalam melakukan program-program kegiatan gerakan literasi. Hal ini menjadi landasan untuk menindaklanjuti program-program tersebut dengan bekerjasama dengan pemerintah nagari, dan seluruh elemen masyarakat. Mengingat Nagari Sungai Nyalo meruapakn Nagari Binaan Universitas Negeri Padang, baik yang berhubungan dengan pariwisata maupun pendidikan, seperti adanya Kampung Inggris yang dicanangkan oleh Rektor UNP Prof. Ganefri yang digawangi oleh Dr. Siti Fatimah. Koordinasi dan kerjasama dengan tim Nagari Binaan menjadi hal yang sangat penting untuk dilakukan. Agar Gerakan Literasi bisa menjadi salah satu bagian dari program Nagari Binaan Universitas Negeri Padang kedepannya. Keberlanjutan program Rumah Literasi merupakan hal yang sangat penting, karena diyakini Rumah Literasi mampu meningkatkan motivasi meraih pendidikan yang lebih tinggi, khususnya bagi anak-anak Nagari Sungai Nyalo.

\section{DAFTAR PUSTAKA}

Kamus Besar Bahasa Indonesia.

bangka.tribunnews.com, diakses pada 1 April 2019, pukul 10.05 Wib.

florespost.co.id, diakses pada 1 April 2019, pukul 11.00 Wib

Gramedia.co.id, diakses pada 10 April 2019, pukul 09.15 Wib.

Humas.unp.ac.id, diakses pada 10 April, pukul 10.00 Wib.

Kemdikbud.go.id, diakses pada 10 April, pukul 09.30 Wib. 